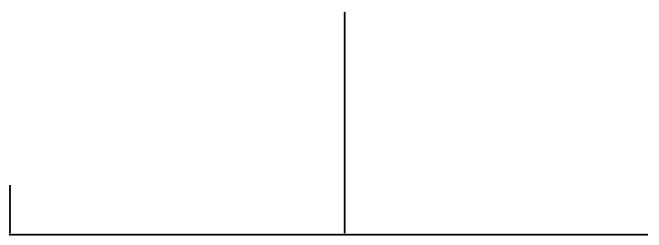

Rev. Latinoam. Psicopat. Fund., São Paulo, v. 15, n. 3, p. 524-539, setembro 2012

\title{
Desinserção social e habitação: a psicanálise na reforma psiquiátrica brasileira*
}

\author{
Cláudia Maria Generoso \\ Andréa Máris Campos Guerra
}

Em pesquisa multicêntrica e interdisciplinar sobre dispositivos de habitação para portadores de transtornos mentais no Brasil, a psicanálise hipotetiza que o modo de apropriação da moradia é decorrência do estilo da desinserção do sujeito. Diferente da desadaptação ou da exclusão, a desinserção é o ponto a partir do qual o sujeito, habitando o desencontro entre linguagem e corpo, articula-se no mundo. Conclui-se, com caso clínico, que a desinserção reflete a exceção constitutiva do sujeito como falta no Outro, a partir do que ele se nomeia e se localiza - aspecto-chave para a clínica psicossocial.

Palavras-chave: Saúde mental, reforma psiquiátrica brasileira, serviços residenciais terapêuticos, psicanálise

* Este artigo só se tornou possível graças à intervenção de Fernanda Otoni de Barros-Brisset em Reunião Científica da pesquisa "Inserção social e habitação: pesquisa avaliativa de moradias de portadores de transtorno mental grave", coordenada por Juarez Furtado da Universidade Federal de São Paulo - Unifesp e financiada pelo Conselho Nacional de Desenvolvimento Científico e Tecnológico - CNPq (Brasília, DF, Br). Nesse encontro, ela nos apresentou a ideia de desinserção aplicada à clínica com as psicoses, cujos principais argumentos encontram-se aqui dispostos e desenvolvidos. 


\section{Desinserção não é desadaptação}

Tradicionalmente a loucura habitou o espaço discursivo da desadaptação moral ou social, tendo ganhado no espaço da reclusão hospitalar seu destino durante séculos. O pareamento estabelecido entre a psiquiatria e o direito para manutenção da ordem social na modernidade se fortaleceu e a loucura se consolidou nos sistemas classificatórios como patologia, digerida em sinais e sintomas que justificavam seu isolamento (Foucault, 1995). Finalmente, na contemporaneidade, não encontramos mais um ideal unificador que articule o tecido social, mas antes a dispersão (identitária) como marca de suas nesgas. Nesse tecido polimorfo, no qual cabem igualmente as diferenças e os preconceitos, a loucura, silenciada enquanto obra, torna-se matriz do desencontro com o Outro, da desinserção.

A partir da noção de desinserção, a psicanálise traz sua contribuição à discussão das formas de habitação empreendidas por psicóticos. Sua novidade é a de reintroduzir a dimensão subjetiva, a inscrição no laço social e a forma como o sujeito pode se destacar dessa trama. Assim, nos permite ler e operar de forma diferente com a clássica noção de exclusão social, recuperando o estilo do sujeito como forma de se articular ao texto da civilização. Nesse sentido, não há desadaptação, mas antes, singulares formas de habitação face à cultura.

\section{A desinserção para a psicanálise}

O termo desinserção social é antigo, tendo sido retomado no contexto da sociologia francesa. Hoje ele se redefine a partir do discurso analítico. Enquanto Guyennot, nos anos 1930, afirmava que a palavra "inserção" qualificava a relação indivíduo-sociedade, H. Bergson a utilizava referindo-se à integração em um grupo. Em outra 
obra L'insertion, Guyennot insistiu sobre a polissemia dessa palavra e seu emprego corrente desde os anos 1960. Já em 1994, Vincent de Gaulejac e Isabelle Taboada escreveram um livro La lutte des places, cujo subtítulo era "Insertion et désinsertion" (Le Champ Freudien, 2009).

Ora, se o desejo do mestre, da civilização, é o de que tudo funcione por homogeneização, sem falhas, a psicanálise sabe que a falha é irredutível, que o gozo não se erradica e que a singularidade não faz norma. A contribuição da psicanálise à coisa pública é exatamente a de mostrar que o gozo não se estanca, mas pode se tornar possível e domesticado via sintoma. Suportar o que faz exceção seria, hoje, uma das maneiras de contribuir com o pacto civilizatório. Resgatar a dimensão subjetiva presente nas singulares modalidades de desinserção e as vias que permitem, a partir do sintoma de cada um, retomar sua inscrição na trama social, seria sua pragmática. Nesse sentido, contra a precariedade simbólica dos sujeitos em lidar com o mal-estar na civilização, a psicanálise opera de forma a que os sujeitos aprendam, no seu estilo, a saber-fazer com isso (Miller, 2003).

Ao trabalhar a lógica constitutiva do sujeito, enquanto sujeito do inconsciente, Lacan (1961-1962) nos ensina que ele acede à linguagem a condição de uma perda essencial de seu ser. Da experiência com o campo da alteridade, com o Outro simbólico e prévio, extrai-se o traço com o qual o sujeito se identificará para poder nomear-se. Se, na experiência original com a realidade, o ser comparece enquanto corpo, a partir do ato de incorporação do traço unário - unidade diferencial mínima -, ele terá um substrato sobre o qual apoiar-se simbolicamente.

De saída, o ser é o corpo e o nome próprio, vazio de significação - corpo e nome próprio disjuntos. Somente com o ato de consentimento ao Outro, o sujeito incorpora a lei do desejo, sob a forma mítica de pai morto, reduzido ao significante. E a substancializa, efetivando-a e conferindo-lhe seu valor simbólico ao assumi-la a partir da incorporação do nome próprio, que se encontra com o corpo. Aí se opera uma dupla perda: 1) perda de gozo no corpo, agora simbolizado pela palavra (ser), e 2) perda de sentido, já que o nome próprio, em si mesmo, é vazio de significação, unidade diferencial mínima a qual permite, a partir dela, que os significantes possam articular novos significados (Outro). A partir dessa dupla perda, o sujeito acede à linguagem e pode, então, falar em nome próprio. Assim, essa relação originária com o Outro é também a relação originária do sujeito com o significante. Por meio dela, o sujeito se constitui, ao fazer-se representar por um significante do Outro. Da perda essencial produzida pela articulação entre linguagem, significante, corpo e gozo, a desinserção ganha forma, assinalando a disjunção aí forjada. 


\section{Desinserção não é exclusão}

Como se vê, há no nascimento do sujeito uma desinserção originária, estrutural. Primeiro corpo e nome disjuntos, depois dupla perda como condição para nomeação e assunção do sujeito ao campo do Outro. Essa primeira identificação, que comporta a inscrição do significante no sujeito, é o que há de mais apagado do primeiro encontro com o objeto. Ela denuncia uma perda originária, ponto a partir do qual inconsciente e desejo se estruturam. É sobre o apagamento desse traço que, por sua vez, o sujeito poderá falar de si. "O sujeito está, se permitem dizê-lo, em uma exclusão interna a seu objeto" (Lacan, 1998, p. 822-23).

A “exclusão”, assim, em psicanálise, é lógica e necessária para que, do vazio que dela se instala, o sintoma possa advir como amarração possível do sujeito ao campo do Outro. O sintoma, nessa perspectiva, é menos a proliferação do mal-estar que seu tratamento possível no laço civilizatório. Ele é a consequência lógica e estrutural da constituição do sujeito, e não um mal a ser extirpado. Se o sujeito "encontra sua morada num ponto situado no Outro" (Lacan, 1962-1963, p. 58), fato é que o faz à custa do sintoma, do que perde de gozo e de sentido ao se inscrever na linguagem. E essa perda nunca se recupera, ela é o preço da entrada na civilização. É o real ${ }^{1}$ em jogo no processo civilizatório.

Jacques-Alain Miller (2004-2005), trabalhando sobre o final do ensino de Lacan, introduz o sintoma como real no vínculo social, permitindo tratar a desinserção como um dos nomes do real de nossa época. Nesse sentido, quanto mais fizer obstáculo à existência subjetiva e ao desejo, mais insuportável será um sintoma - motivo pelo qual ele se torna um elemento central e operatório no trato com a desinserção. Sob a ótica da psicanálise, o fora da norma, então, não se apresenta como "desadaptação" ou "exclusão", ao contrário, é acolhido e ganha seu valor central na forma de resistência, invenção subjetiva.

Se não há satisfação plena e se não há norma universal, resta a cada um inventar uma solução particular, que se apoie sobre seu sintoma. A solução de cada um pode ser mais ou menos típica, mais ou menos apoiada sobre a tradição e as regras comuns. Ou pode, ao contrário, desejar realçar a ruptura ou uma certa clandestinidade (Laurent, 2006).

1. Lacan concebia a realidade como o resultado da amarração entre três registros: o real ou aquilo que é da ordem do dado, que tem um certo valor bruto; o imaginário ou aquilo que é representado enquanto imagem; e o simbólico ou o que é estruturado e articulado como linguagem (Miller, 2002, p. 10). 
Assim, a psicanálise não pode determinar sua direção e seu fim em termos de adaptação da singularidade às normas. Ela aborda, ao contrário, a impotência do sujeito em alcançar a satisfação plena, o que se denomina castração. E, em seu percurso, busca conseguir que cada sujeito encontre um certo acordo de convivência consigo mesmo e com a civilização. No um a um, podem-se abrir novas vias que permitam aos sujeitos extrair o necessário saber-fazer com seu sintoma para ultrapassar os obstáculos e as consequências subjetivas da desinserção.

\section{Desinserção e loucura junto às formas de habitação}

Com a dimensão do inconsciente, a psicanálise reinterpreta a experiência da loucura fora do eixo Razão-Desrazão. Em sua ótica, a desinserção, diferente da exclusão social ou da desadaptação, se coloca para todos. A psicose, termo técnico que designa a loucura, é efeito de um posicionamento de rejeição radical do sujeito diante da linguagem, diante da impossível síntese, ou interseção, entre sujeito e Outro. Nesse sentido, leva ao extremo a experiência da desinserção, fazendo-se paradigma de seus modos de solução. O psicótico é o sujeito, por excelência, que aprendeu a lidar, a saber-fazer com seu sintoma, seja por meio do delírio, da arte ou de outro recurso. Ele nos mostra o uso possível do sintoma na radicalidade da vivência do desamparo em relação ao Outro.

O tratamento construído pelo psicótico para tratar dessa disjunção com o corpo e com o Outro é a direção seguida para lidar com sua desinserção originária. Com isso, sua palavra ganha um valor central na clínica. Além disso, a singularidade de sua história e do estilo que constrói em decorrência dessa posição face à linguagem demarcam a lógica de sua posição subjetiva e de seu pacto com a civilização. Não há o que adaptar ou incluir, mas antes o que suportar desse embaraço da experiência da loucura com a civilização, estabelecida a cada caso. Assim, as experiências de apropriação das moradias pelos psicóticos obedecerão a essa lógica singular de funcionamento de cada sujeito.

Hipotetizamos que o modo como o sujeito vai se apropriar de sua moradia, em outras palavras, o estilo que constrói de habitação de um espaço de vida ou de residência, é decorrência do estilo de sua desinserção. Assim, encontramos na exceção que funda a posição de Vitor no mundo, o modo como a desinserção se presentifica e é trabalhada por ele na construção de sua moradia. Usuário da rede pública de Saúde Mental, Vitor prescindiu de um serviço residencial terapêutico e construiu, a sua maneira, um modo de habitar a vida e sua casa. A construção de seu caso se deu a partir de uma pesquisa de avaliação na qual a psicanálise, com seu método clínico, foi convidada a participar. 


\section{SAÚDE MENTAL}

\section{A desinserção como índice para pensar a habitação: um caso clínico}

Vitor, atualmente com 53 anos de idade, mora sozinho há oito anos. Vive em um quartinho alugado em um prédio, o qual é denominado pelo proprietário de "cortiço" e pelo próprio Vitor de "pensionato". A história dessa moradia iniciou com a saída de Vitor, aos 44 anos de idade, do hospital psiquiátrico onde permaneceu internado durante três anos, cumprindo medida de segurança devido a homicídio cometido na cidade na qual vivia. Segundo Vitor, gosta de morar sozinho e não pensa em voltar para a cidade onde morou, pois lá aconteceu o fato de ele e uma namorada terem matado o ex-cunhado dele, que já estava caçando confusão há muito tempo. Devido a isso, ficou preso e depois foi transferido para um hospital psiquiátrico na capital do estado onde residia. Sente-se arrependido pelo que fez, e acha que o que já pagou na prisão e no manicômio não é suficiente para ser perdoado por Deus.

O caso de Vitor nos demonstra sua forma de lidar com o caráter de radical exterioridade da linguagem. Esta se delineia por meio de sintomas alucinatórios, tal como as vozes que ouve ou a perplexidade que o leva a não entender mais as palavras, permanecendo em silêncio por um longo tempo por não conseguir falar. A voz simplesmente não saía (...) perdi a voz (...) delirava com as palavras, eu não sabia escolher o que eu ia falar. Esse episódio aconteceu por volta dos 26 anos de idade, o que o levou a iniciar tratamento psiquiátrico por ocasião de sua primeira internação. Em relação às alucinações, ele diz que ouve vozes desde bebê e, já adulto, passou a escrever o que elas falavam. Elas dão bons e maus conselhos e preveem o que vai acontecer com ele no futuro.

Percebemos também uma dificuldade de Vitor em se situar no mundo, em encontrar um lugar desde criança e isso é observado na sua relação com a casa. A dificuldade de habitar os lugares é também uma característica que podemos localizar em seu pai que sempre estava mudando de casa e de cidade. Inicialmente a família morou com a avó paterna em uma roça. Aos seis anos de idade o pai mudou de cidade com a família para viver em um barracão próprio. Em pouco tempo, venderam o barracão e foram morar em uma casa de aluguel. As constantes mudanças de casa são expressas na fala de Vitor: ... a gente ficava mudando de um lugar para o outro, tinha lugar que a gente não ficava nem quinze dias. Tinha uma casa lá que a minha mãe disse que estava assombrada, a gente não ficou nem uma semana. Com sete anos foi com a família para São Paulo, mas retornaram para Minas em pouco tempo, pois o pai não conseguiu emprego. Sobre essas constantes mudanças do pai, Vitor o compara a um cigano, pois teve que fugir com a mãe para casar-se aos 16 anos de idade. Isso deve tê-lo influenciado a não conseguir fincar raiz. 
Ele próprio, Vitor, também não conseguia "fincar raízes" e sempre fugia de casa. Aos 12 anos de idade, fugiu e foi para a capital, chegando a ficar na rua por alguns dias. Tentou ir a pé de sua cidade até São Paulo. Por várias vezes foi para a capital, chegando a morar na rua em muitos momentos. Vitor sempre alegava que saía de casa para procurar trabalho - pois o pai esperava isso dele ou por não aguentar ver os pais brigando. A relação com o pai era muito próxima, sendo que os trabalhos que arranjava eram junto dele. O pai era pintor e carpinteiro e Vitor trabalhava como pedreiro.

Parece que Vitor entrou no estado de errância quando foi trabalhar longe do pai, por volta dos 22 anos de idade, na capital, acompanhando um pintor de sua cidade. Em pouco tempo de trabalho, ele passou a usar drogas de forma intensa e perdeu o controle sobre sua vida. Estava muito desorientado naquela época, fora de si. Longe do pai, Vitor se encontra fora de si. Do pai cigano ao movimento de fincar raízes, vemos seu movimento na tentativa de se alojar na linguagem, de localizar-se simbolicamente no campo do Outro, de tratar, enfim, sua desinserção.

O pai se preocupava com esse jeito do filho, dizia que precisava tomar conta dele mesmo depois de adulto. E lembrava que ele não era bom cumpridor de regras. Dessa forma, o pai achava que Vitor precisava se aposentar para ficar quieto em casa. Ele achava que o fato de o filho sair para procurar emprego acabava levando-o a viver na rua. Conseguiu, então, encaminhar o processo do benefício que o filho recebe desde 1986. Porém, o benefício não o fixou em casa e ele continuou vivendo entre Belo Horizonte, São Paulo e sua cidade natal, sendo que, muitas vezes, morou na rua ou em abrigos. Apesar da função simbólica do benefício, que poderia operar uma forma de inserção no campo do Outro por meio de sua inscrição social, não vemos esse efeito acontecer.

\section{A função do pai no caso de Vitor}

Lacan (1975-1976) nos ensina que é preciso prescindir do pai a condição de dele se servir. No início de seu ensino, Lacan (1955-1956) nos apresenta um pai, cujo valor simbólico zero propicia que o corpo e os fenômenos sociais sejam assimilados pela linguagem, elemento que articula natureza e cultura. O pai teria, pois, o valor estrutural e significante de articular o sujeito na linguagem. Aqui estamos pensando no pai enquanto significante do Nome-do-Pai que, dialetizando o desejo da mãe, permite à criança significar-se.

Ao final de seu ensino, Lacan (1974-1975 e 1975-1976) relativiza o valor estrutural do pai, entendendo que ele é um conectivo, como outros, que pode funcionar articulando pelo Édipo os três registros da realidade. Nesse sentido, ele 


\section{SAÚDE MENTAL}

se torna uma espécie de instrumento do qual o sujeito pode se servir de diferentes maneiras. Na psicose, mais especialmente, o sujeito prescinde do pai e inventa, aos modos da bricolagem, colagens que podem suplenciá-lo na função de amarração dos registros. O psicótico, assim, é um sujeito que cria maneiras originais de comparecer diante do Outro no laço social, evidenciando um saber-fazer com o desamparo original que toca a todos.

No caso de Vitor, vemos o pai comparecer de diferentes formas e, em sua escrita, de maneira original. Podemos observar uma relação especial de Vitor com o morar, constituída a partir do pai como elemento de conexão por meio dela que é outra marca fundamental na vida desse sujeito. Ele demonstra uma relação muito própria com a palavra desde criança. Antes mesmo de saber ler e escrever, já era encantado pelas letras e as copiava de forma a desenhá-las no papel, mesmo sem saber seu significado. Ele via as propagandas afixadas nas ruas e queria saber o que elas diziam. Geralmente copiava as letras, retirando-as dos jornais com que o pai embrulhava alguma coisa que levava para casa (mantimentos etc.). É do real do pai que ele retira elementos para tentar escrever-se no campo do Outro. Das letras do pai, retiradas do jornal, vale-se de seu estilo no esforço de inscrever-se por meio da escrita. Justamente dali, onde originalmente não encontrou um ponto de vetorização subjetiva na linguagem que o localizasse no campo do Outro.

\section{A escrita e o trabalho de construção de uma casa}

Comenta que, por volta dos quatro anos de idade, conseguiu escrever a primeira palavra já sabendo seu significado - "casa" -, e o fez na parede da casa de sua avó paterna, na qual morou quando nasceu, escrevendo-a com um caco de telha. A avó brigou muito e o mandou limpar a parede. Porém, mesmo limpando, as marcas das letras não saíram. As marcas ficaram, mas não foram suficientes para ancorá-lo no habitar que a linguagem poderia amparar. Os momentos de desatrelamento subjetivo foram muitos, tais como podemos observar nos variados sintomas alucinatórios manifestos nas vozes que ouve ou de alguma frase que lê em algum lugar (cartazes, folhetos na rua, no bar), fixando-se em sua cabeça e causando-lhe mal-estar.

Suas tentativas de tratamento para essa ruptura foram muitas, sendo sempre permeadas pela escrita. Escreve as palavras ou frases que se fixam em sua mente e também os conteúdos das vozes que ouve. Geralmente rasgava, e ainda rasga, grande parte da escrita que vem dessa exterioridade que lhe é, a princípio, totalmente estrangeira, pois não sabe se ela está certa, bem como se as pessoas poderão entender o sentido dela. Podemos perceber que ele arranjou uma maneira 
de lidar com esse Outro estrangeiro da linguagem. Ora o faz pela materialidade advinda do ato de escrever, para aliviar sua cabeça das frases que ficam fixadas em sua mente, possibilitando aí um mínimo de separação; ora por meio das vozes que insistem em invadir sua privacidade, seja a voz do demônio, seja a voz de Deus. E rasga estes escritos para sentir-se mais seguro. Então, ao mesmo tempo em que a escrita o alivia, ela também o ameaça.

Quando estava na cadeia também escrevia o que estava fixado em sua cabeça ou o que as vozes mandavam. Lá inventou uma maneira de lidar com a sua escrita que foi colocá-la dentro de sacos plásticos, jogá-los no vaso sanitário e dar descarga. Imaginava que assim essa escrita poderia chegar até Israel (parece que havia alguma missão delirante). Dessa forma, Vitor seleciona o que pode ser publicado, havendo um trabalho no sentido de ele ser mais sujeito do que escreve, ao contrário de quando escreve de forma imperativa, seja comandado pelas vozes, seja comandado pelas frases fixadas em sua mente.

Podemos observar essa seleção em relação ao seu trabalho de escrever para o jornalzinho do CAPS, onde faz tratamento desde 2006. Ele ganhou o codinome Voa-Voa ${ }^{2}$ com o qual assina seus escritos, que são endereçados a três seções do jornal: Loucomotivo, Informeação e Atualidades. Podemos dizer que, para Vitor, uma das funções do CAPS é ser um lugar no qual pode publicar seus escritos, podendo endereçá-los aos outros, tal como faz ao dar os jornais para a irmã que os coleciona.

Além disso, destaca-se, nessa nomeação, um elemento de apaziguamento do gozo, um tratamento do real, que o avassala, pelo simbólico do nome. "Voa-Voa" condensa, aos moldes de uma metáfora, um nome próprio, cuja assinatura deixa sua marca de autoria no Outro. Ao mesmo tempo, nomeia sua ausência de "raízes", fazendo às vezes da função paterna ao vetorializar sua posição subjetiva. Parece-nos, pois, constituir um elemento fundamental para o apaziguamento e para a localização desse sujeito no campo do Outro.

Podemos pensar que, em seu trajeto pela prisão e posteriormente pelo hospital psiquiátrico e pelo CAPS, ele encontrou pessoas que tiveram a função de um outro com o qual poderia conversar, endereçar seus escritos, delineando um tratamento que não era mais tão solitário. Foi na prisão que parou de rasgar todos seus escritos, a partir do momento que a médica os valorizou e o aconselhou a não rasgá-los. No hospital, conversava com sua médica e os profissionais do

2. VOA-VOA: refere-se às iniciais do nome de Vitor de Oliveira Alves (pseudônimo adotado no texto para evitar sua identificação), sendo tal codinome sugerido pelo coordenador da oficina de Jornal do CAPS.

Rev. Latinoam. Psicopat. Fund., São Paulo, v. 15, n. 3, p. 524-539, setembro 2012 


\section{SAÚDE MENTAL}

Programa de Atendimento Integral a Pacientes Judiciários ${ }^{3}$ sobre os temas relacionados ao crime, à culpa, ao juiz, à sua liberação, à medicação. No CAPS encontrou uma via de publicação dos escritos no jornalzinho, sendo os mesmos frutos de elaborações mais próprias. Dessa forma, destacamos a importância do tratamento para esse sujeito que contribuiu na construção de um lugar mais possível para viver.

\section{Vitor e sua morada no campo do Outro}

Sendo assim, a moradia que mais fixou Vitor em um lugar é a atual, na qual vive há oito anos. Ela surgiu após a alta de Vitor do hospital psiquiátrico, no qual cumpriu medida judicial, mas com a condição dada pelo juiz de ele continuar o tratamento. Saindo da internação, continuou em tratamento por mais algum tempo no hospital-dia, vinculado ao hospital, e foi organizando sua vida na cidade. Decidiu continuar na capital porque interpretou que o juiz assim o determinou. Não quer voltar para a sua cidade porque tem medo de ser morto ou matar alguém lá, devido ao crime que cometeu. Procurou alguns lugares para morar e escolheu aquele que nomeia de "pensionato". É um lugar destinado apenas a homens que moram sozinhos, ficando a seleção dos moradores a cargo do dono do prédio-cortiço. Prisão, hospital, pensionato tornaram-se pontos de fixação e orientação desse vetor quanto à construção da possibilidade de habitar um espaço concreto e simbólico.

A história de Vitor nos leva a pensar que a possibilidade de habitar minimamente um lugar por mais tempo contou com a contribuição da figura do juiz, representante da lei, que determinou para ele algumas regras como, por exemplo, ficar em Belo Horizonte, fazer tratamento. Atrelado a isso, ele encontrou um lugar em que os donos parecem exercer a função de ajudar a tomar conta dele, mas sem serem invasivos. Estão atentos à sua medicação, à manutenção do quarto, preocupam-se quando ele não sai do quarto, retomando uma via apontada por ele de que precisava de alguém para cuidar dele, tal como seu pai dizia, mas dentro de uma medida.

Chama-nos atenção de que Vitor é um grande defensor dos manicômios e das prisões, pois os considera como lugares da ordem, do cuidado, das regras. Nesses lugares, há sempre alguém tomando conta. Já destacamos que, na relação

3. O PAI-PJ é um Programa do Tribunal de Minas Gerais que acompanha a aplicação da medida de segurança a psicóticos que cometeram crimes.

Rev. Latinoam. Psicopat. Fund., São Paulo, v. 15, n. 3, p. 524-539, setembro 2012 
com o Outro, ele espera ser vigiado para não fazer coisas erradas, tal como no dia do crime. As pessoas têm que vigiar as outras. Olha só o que ocorreu!, referindo-se à namorada que deveria ter evitado isso. Ser vigiado por alguém remete à sua relação com o hospital psiquiátrico, local "mais seguro" para viver porque sempre tem alguém que olha e não deixa a confusão acontecer. Por essa razão, é contra o fechamento dos mesmos. Sente que a vida em liberdade, fora do hospital, é mais perigosa. Acha que é importante ter regras e horários para diminuir a violência, tal como o toque de recolher. Isso nos remete à relação com o pai que sempre dizia ter de tomar conta dele, mesmo depois de adulto.

Nesse contexto, Vitor construiu uma rotina para seu dia-a-dia, determinada pelo que ele precisa fazer, por regras e obrigações, tal como ele as nomeia: ida ao restaurante popular três vezes ao dia para fazer suas refeições, fazer o jogo na loteria da rodoviária, idas quinzenais ao CAPS para consultas e participação na oficina de jornal, idas à barbearia do bairro, ao alfaiate e ao posto de saúde, quando necessário. Aos finais de semana, vai a um restaurante próximo àquele popular e volta para casa. Não gosta de sair à toa, pois isso queima o filme, sendo seu dia a dia marcado por essa rotina de realização do necessário, demarcando um lugar mais possível e protegido para viver, sob o amparo do dever e das obrigações.

\section{Desinserção, loucura e singularidade na construção da moradia por Vitor}

Assim, articula-se para Vitor uma nova ordem, agora orientada por um Outro mediador, dialetizado na figura do juiz e da lei. Ele não se encontra mais submetido a uma ordem imperativa, tal qual a do pai, que tomava conta dele, dirigindo sua vida. O juiz, ao mesmo tempo em que toma conta e dá orientações, deixa ao sujeito uma hiância, um espaço por meio do qual ele pode construir suas soluções, orientando-se pelas indicações que ele lê no outro. Dali, ele não precisa fugir. Assim também o dono do pensionato oferece uma mediação a boa distância, apresentando regras de convivência a serem obedecidas por todos os moradores do cortiço. Ou seja, ele passa da regulação do cotidiano por um Outro não dialetizável para o compartilhamento do cotidiano, regulado pela lei que se dirige a todos. A lei, que regula a todos, deixa de ser caprichosa e dirigida apenas a ele - como era a regulação do pai -, cumprindo sua função de composição no laço social.

Além dessa função reguladora do laço social, encontramos também outra estratégia de Vitor quanto ao gozo e à relação com o objeto. Em seu quarto-casa, podemos observar as marcas da sua escrita desenhada na parede ou no corpo. Elas aparecem, por exemplo, na cruz feita a lápis na parede ao lado da cama, a 


\section{SAÚDE MENTAL}

qual é nomeada por ele de cruz de fé ou no número de telefone da mãe, anotado na parede. No corpo, por outro lado, há algumas tatuagens de números, âncoras. A escrita também imprime suas marcas em outro suporte, o caderno, guardado em sua mala, e ao qual ele recorre para escrever tanto o que é para ser rasgado, quanto o que é para ser mostrado às visitas ou ao CAPS. Parece-nos que, com essa estratégia, ele tenta conferir um contorno ao objeto voz, posto que continua a ouvir as vozes do bem e do mal.

Assim, se a lei e os outrinhos (juiz, dono do pensionato, técnicos do CAPS) oferecem uma regulação pelo simbólico que lhe permite situar-se no Outro e constituir uma habitação para si, a escrita funciona na regulação do gozo, conferindo um tratamento real ao objeto-voz, modulado fora do corpo e endereçado ao laço social. E, com a escrita, torna-se mais familiar a dimensão estrangeira de sua relação com o Outro. Trata, assim, ao menos sob essas duas vertentes, sua desinserção, aprendendo a lidar com isso que lhe escapa.

As marcas de seu estilo também podem ser vistas na disposição dos objetos de seu quarto, em cima do criado ao lado de sua cama: o rádio no qual só ouve diariamente o programa "Voz do Brasil", o celular, um apito que serve para acionar os vizinhos quando precisa, seus óculos, o pente de cabelo, muitas canetas e vários papéis espalhados. Em sua cama, há a marca de seu corpo delineada no colchão e na parede, demarcando a posição em que se habituou a ficar quando está dedicado à sua escrita.

Para concluir, podemos dizer que a habitação de Vitor demonstra um saber lidar com a vertente do mal-estar do sintoma que se apresenta de forma estrangeira. Foi a partir dos pedaços da linguagem estrangeira, presença de gozo expresso nas desconexões com o Outro, que ele cerziu sua forma de habitar a vida, bricolando uma possibilidade de presença no laço social.

Dessa forma, tomamos o modo de habitação de Vitor para afirmar nossa hipótese levantada acima, uma vez que esse caso demonstra que é necessário considerar a desinserção no trabalho junto às possibilidades de construção da habitação por portadores de sofrimento mental grave no campo da Reforma Psiquiátrica Brasileira.

\section{Desinserção: uma ferramenta operatória da Psicanálise para a Reforma Psiquiátrica Brasileira}

Com a psicanálise, aprendemos que cada sujeito é único, e o modo de se alienar de sua exceção constitutiva é se arranjar com o Outro, partilhando sentidos que o singularizam no universo simbólico oferecido pelo discurso social que o 
constitui. Assim, quando algo do singular - do que não se inclui ou se insere se fixa, o sujeito encontra seu modo de funcionamento no laço social. O sujeito encontra um modo de saber-fazer com sua ausência no Outro - seu sintoma -, e ali constrói sua morada simbólica. A inclusão, nesse sentido, teria de considerar o ponto de exceção que inclui o sujeito na ordem das coisas - o que não se confunde nem com desadaptação, nem com exclusão. Ao contrário, sua desinserção se constitui como solução - dimensão positiva, que causa trabalho de enlaçamento a partir da exceção que particulariza seu modo de estar no mundo.

\section{Referências}

Foucault, M. História da loucura na Idade Clássica. 4. ed. São Paulo: Perspectiva, 1995. Lacan, J. Subversão do sujeito e dialética do desejo no inconsciente freudiano. In: Escritos. Rio de Janeiro: Jorge Zahar, 1998. p. 807-842.

Lacan, J. (1955-1956). O seminário. Livro 3. As psicoses. Tradução de Aluísio Menezes. Texto estabelecido por Jacques Alain-Miller. 2. ed. Rio de Janeiro: Jorge Zahar, 1992.

LaCan, J. (1961-1962). O seminário. Livro 9. A identificação. Inédito.

LaCAN, J. (1962-1963). Além da angústia de castração. In: O seminário. Livro 10. A angústia. Rio de Janeiro: Jorge Zahar, 2005. p. 53-65.

Lacan, J. (1974-1975). Le seminaire. Livre 22. RSI. Inédito. Disponível em <http:// gaogoa.free.fr/>.

LACAN, J. (1974-1975). Livre XXII, RSI. Ornicar?, Paris, n. 02-05, 1975-76.

Lacan, J. (1975-1976). Le seminaire. Livre XXIII. Le sinthome. Texte établi par Jacques-Alain Miller. Paris: Seuil, 2005.

Laurent, É. Principes directeurs de l'acte psychanalytique. Paris: École de la Cause Freudienne, 2006. Consultado em 8 de janeiro de 2010 em <http://www.causefreudienne. net/index.php/ecole/textes-fondateurs/principes-directeurs-de-l-acte-psychanalytique> .

Le Champ Freudien. Un nuevo termino: la desinserción. Buenos Aires, 2009. Consultado em: 8 de janeiro de 2010 em: <http://ri2009.champfreudien.org/index.php?nav=5> Miller, J-A. O real é sem lei. Opção lacaniana - Revista Brasileira Internacional de Psicanálise, São Paulo, n. 34, p. 7-16, out. 2002.

Miller, J-A. Rumo à PIPOL 4. Correio - Revista da Escola Brasileira de Psicanálise, São Paulo, n. 60, p. 7-14, 2003.

Miller, J-A. Pièces detachés. Séminaire Orientation Lacanienne III, 6, 2004-2005. Inédito. 


\section{SAÚDE MENTAL}

Resumos

(Social Detachment and Living Arrangements: Psychoanalysis in the Brazilian Psychiatric Reform)

In a multicentered and interdisciplinary study on housing solutions for persons with mental disorders in Brazil, psychoanalysts have hypothesized that the mode of appropriation of housing is the result of the style of the detachment of this population. Unlike the concepts of exclusion and failure to adapt, detachment refers to the point from which the subject, inhabiting the disparity between language and body, connects with the world. We conclude with a clinical case, holding that detachment reflects the constitutive exception of the subject as a lack in the Other, from which he assumes his name and finds his place - factors that are keys elements in the psychosocial clinic.

Key words: Mental Health, psychoanalysis, Brazilian Psychiatric Reform, therapeutic residential services

(Désinsertion sociale et logement: la psychanalyse dans la réforme psychiatrique brésilienne)

Selon une recherche multicentrique et interdisciplinaire sur des dispositifs de logement pour les personnes atteintes de troubles mentaux au Brésil, la psychanalyse soutient l'hypothèse que le mode de s'approprier du logement dépend du style de la désinsertion $d u$ sujet. Contrairement à l'inadaptation ou à l'exclusion, la désinsertion est le point à partir duquel le sujet, qui habite le décalage entre le langage et le corps, s'articule dans le monde. À l'aide d'un cas clinique, nous concluons que la désinsertion reflète l'exception constitutive du sujet comme manque dans l'Autre, ce qu'il utilise pour se nommer et se situer - un aspect clé pour la clinique psychosociale.

Mots clés: Santé mentale, psychanalyse, réforme psychiatrique brésilienne, Services résidentiels thérapeutiques

(Des-inserción social y habitación: el psicoanálisis en la reforma psiquiátrica brasileña)

En una investigación multicéntrica (realizada en varios centros de atendimiento?) e interdiciplinar a respecto de los dispositivos de vivienda para personas con trastornos mentales en Brasil, se utilizó la hipótesis psicoanalítica de que el modo de apropiación de la vivienda es consecuencia del estilo de des-inserción del sujeto. Diferente de la inadaptación o de la exclusión, la des-inserción es el punto en que el sujeto que vive en el desencuentro entre el lenguaje y el cuerpo, se articula en el mundo. Se concluye, ilustrando con un caso clínico, que la des-inserción refleja la constitución exceptiva del sujeto como una falta en el Otro, desde la cual el sujeto se nombra y se ubicaaspecto clave para la clínica psicosocial.

Palabras clave: Salud mental, reforma psiquiátrica brasileña, los servicios residenciales terapéuticos, psicoanálisis

Rev. Latinoam. Psicopat. Fund., São Paulo, v. 15, n. 3, p. 524-539, setembro 2012 
(Soziale Isolierung und Wohnen: Die Psychoanalyse in der Reform der brasilianischen Psychiatrie)

In einer multizentrischen und interdisziplinären Untersuchung über die Wohnmöglichkeiten für Geistesgestörte in Brasilien, stellt die Psychoanalyse die Hypothese auf, dass die Art der Wohnungsbesetzung eine Folge der Isolierung des Menschen ist. Anders als das "Entfähigen" oder das Ausschließen, ist die Isolierung der Ausgangspunkt von dem aus der Mensch, der die Abweichung zwischen Sprache und Körper innehat, sich in der Welt bewegt. Die Schlussfolgerung, mit einem klinischen Fall, ist, dass die Isolierung die konstitutive Ausnahme des Menschen als Mangel im Anderen wiedergibt; und davon ausgehend benennt und orientiert er sich - ein Schlüsselaspekt für die psychosoziale Klinik.

Schlüsselwörter: Geistige Gesundheit, Reform der brasilianischen Psychiatrie, therapeutische Wohnungsdienstleistungen, Psychoanalyse

Citação/Citation: Generoso, C.M.; GuERra, A.M.C. Desinserção social e habitação: a psicanálise na reforma psiquiátrica brasileira. Revista Latinoamericana de Psicopatologia Fundamental, São Paulo, v. 15, n. 3, p. 524-549, set. 2012.

Editor do artigo/Editor: Profa. Dra. Ana Cristina Figueiredo

Recebido/Received: 25.10.2011 / 10.25.2011 Aceito/Accepted: 23.1.2012 / 1.23.2012

Copyright: () 2009 Associação Universitária de Pesquisa em Psicopatologia Fundamental/ University Association for Research in Fundamental Psychopathology. Este é um artigo de livre acesso, que permite uso irrestrito, distribuição e reprodução em qualquer meio, desde que o autor e a fonte sejam citados / This is an open-access article, which permits unrestricted use, distribution, and reproduction in any medium, provided the original author and source are credited.

Financiamento/Funding: As autoras declaram não ter sido financiadas ou apoiadas / The authors have no support or funding to report. 
Conflito de interesses/Conflict of interest: As autoras declaram que não há conflito de interesses / The authors declare that has no conflict of interest.

\section{Cláudia Maria Generoso}

Doutoranda em Psicologia/Estudos Psicanalíticos pela Universidade Federal de Minas Gerais UFMG (Belo Horizonte, MG. Br); Psicóloga da rede de Saúde Mental de Betim-MG (Centro Referência Saúde Mental e Serviço Residencial Terapêutico).

Av. Brasil, 1831, sala 1011

30140-901 Belo Horizonte, MG, Br

Fone: (31) 9614-4466

e-mail: claudia.generoso@yahoo.com.br

\section{Andréa Máris Campos Guerra}

Doutora em Teoria Psicanalítica pela Universidade Federal do Rio de Janeiro - UFRJ (Rio de Janeiro, RJ, Br)/Rennes II-França; Professora Adjunta do Departamento de Psicologia da Universidade Federal de Minas Gerais - UFMG (Belo Horizonte, MG, Br).

Av. Contorno, 5351, sala 701

30110-060 Belo Horizonte, MG, Br

Fone: (31) 8489-4548

e-mail: aguerra@uai.com.br 